\title{
Prevalence of Ankyloglossia among Children Reporting with Speech Pathology to District Early Intervention Centre (DEIC)- An Observational Study
}

\author{
Ponranjini Vedeswari Chandrasekaran¹, Jaganbabu Palaniappan², Appadurai Rajendran³, \\ Balaji Venugopal ${ }^{4}$, Pamalai Gnanamoorthy ${ }^{5}$
}

\begin{abstract}
${ }^{1}$ Department of Dental Surgery, Government Villupuram Medical College, Villupuram, Tamilnadu, India. ${ }^{2}$ Department of Dental Surgery, Government Vellore Medical College, Vellore, Tamilnadu, India. ${ }^{3}$ Department of Dental Surgery, Government Villupuram Medical College, Villupuram, Tamilnadu, India. ${ }^{4}$ Department of Dental Surgery, Government Villupuram Medical College, Villupuram, Tamilnadu, India. ${ }^{5}$ Department of Dental Surgery, Government Villupuram Medical College, Villupuram, Tamilnadu, India.
\end{abstract}

\section{ABSTRACT}

\section{BACKGROUND} and immobile elements of the articulation system. Tongue being one of the important mobile elements if restricted may lead to difficulty in articulation of one or more sounds. However, the relationship between speech and ankyloglossia is less investigated. So, we conducted a study to evaluate the prevalence of ankyloglossia among children with speech pathology reporting to District Early Intervention Centre (DEIC).

\section{METHODS}

An observational study was conducted in the Department of Dental Surgery in association with DEIC of a tertiary care hospital for a period of one year. Children reporting for evaluation of speech pathology between 3 and 11 years of age were examined. Children with a history of traumatic injury or any surgical / chemo radiation treatment to oral cavity were excluded from the study.

\section{RESULTS}

Among the total of 8911 patients who visited DEIC, 380 patients were referred for evaluation of speech difficulty. Among them a total of 304 patients were diagnosed with ankyloglossia. The overall prevalence of ankyloglossia was 3.4 percent and that among patients with speech problem was 80 percent. The prevalence was distributed as 63.5 percent in males and 36.5 percent in females. Type 2 ankyloglossia was highly prevalent (72 percent) than the others.

\section{CONCLUSIONS}

A substantial proportion of children with speech problem had ankyloglossia (80 percent). So, all the children with speech difficulty should be screened for ankyloglossia and correction undertaken. Awareness should be created among the common people about ankyloglossia, and the treatment options available.
A sound is produced as a result of various movements and positions of the mobile

\author{
Corresponding Author: \\ Dr. Jaganbabu Palaniappan, \\ \#9/43, Thandavarayan Street, \\ Velapadi, Vellore, \\ Tamilnadu, India \\ E-mail: drjaganbabu@gmail.com
}

DOI: $10.14260 /$ jemds/2020/185

Financial or Other Competing Interests: None.

How to Cite This Article:

Chandrasekaran PV, Palaniappan J,

Rajendran $A$, et al. Prevalence of ankyloglossia among children reporting with speech pathology to district early intervention centre (DEIC)- an observational study. J. Evolution Med. Dent. Sci. 2020;9(11):860-862, DOI: $10.14260 /$ jemds/2020/185

Submission 10-01-2020,

Peer Review 20-02-2020,

Acceptance 26-02-2020,

Published 16-03-2020.

\section{KEY WORDS}

DEIC, Speech Pathology, Ankyloglossia, Prevalence 


\section{BACKGROUND}

Clarity of speech is one of the essentials for good psychosocial development of a child through which they display their expressions. Children with speech difficulty often experience psychosocial stigma. A sound is produced as a result of various movements and positions of the mobile and immobile elements of the articulation system. Tongue being one of the important mobile elements if restricted may lead to difficulty in articulation of one or more sounds. ${ }^{1}$ Ankyloglossia or tongue tie by definition is the limitation of protrusion and elevation of tongue tip due to shortened lingual frenulum and or genioglossus muscle. It is due to incorrect division of muscles of the floor of the mouth with defective cellular apoptosis during embryogenesis between tongue and floor of mouth resulting in short fibrous lingual frenulum. Such anterior attachment of lingual frenulum greatly influences oral physiological functions like sucking, swallowing, occlusion, speech, oral hygiene measures and other masticatory and social factors. ${ }^{2}$

Ankyloglossia might hamper the development of acoustic - articulatory stereotypes as the child may limit to produce words by imitation leading to articulation difficulty. The lowered tongue position with limited mobility and altered posture for various sound productions results in a compromised production of consonants and sounds like s, $\mathrm{z}, \mathrm{t}$, $\mathrm{d}, \mathrm{l}, \mathrm{j}$, zh, ch, th, dg and particularly ' $r$ '. ${ }^{3}$ The varying degrees of ankyloglossia will determine the severity of the problem. However, in mild conditions with minimal symptoms the problem goes undiagnosed and the prevalence is underestimated and also the relationship between speech and ankyloglossia is less investigated. So, the objective of this study is to determine the prevalence of ankyloglossia among children with speech pathology.

\section{METHODS}

An observational study was conducted in the Department of Dental Surgery in association with District Early Intervention Centre (DEIC) of our tertiary care hospital. The study population included all children between 3 to 11 years of age who were referred for evaluation for speech difficulty for a period from June 2018 to July 2019. Children with a history of traumatic injury to tongue and any surgical or chemo radiation treatment were excluded from the study. Informed consent was obtained. Their demographic data was recorded and then the children were evaluated by a speech therapist. Then they were subjected to oral examination. The tongue was examined for protrusion and elevation. The diagnosis of ankyloglossia was based on Coryllos classification which describes the following types of lingual frenulum.; Type 1: fine elastic frenulum; tongue is anchored from the tip to alveolar ridge and it is heart shaped; Type 2: fine elastic frenulum; tongue is anchored 2 to $4 \mathrm{~mm}$ from tip to almost near the alveolar ridge; Type 3: thick fibrous non elastic frenulum; tongue is anchored from middle of tongue to floor of mouth; Type 4: frenulum cannot be seen but palpated; it has a fibrous and / or thick shiny submucous anchoring from base of tongue to floor of mouth. The data was analysed and the prevalence of ankyloglossia was estimated as percentage.
RESULTS

A total of 8911 patients visited the Department of Dental Surgery in DEIC. They were in the age group of 3 to 11 years. Among them 380 patients were referred for evaluation of speech pathology. In the group of children with speech difficulty a total of 304 patients were diagnosed with ankyloglossia. The overall prevalence of ankyloglossia was 3.4 percent and that among patients with speech problem was 80 percent (table 1). The prevalence was distributed as 63.5 percent in males and 36.5 percent in females (table 2). The type 2 ankyloglossia was highly prevalent (72 percent) than the others; type 1 (1.6 percent), type 3 (23 percent), type 4 (3 percent) (table 3 ).

\begin{tabular}{|ccc|}
\hline Sl. No. & Subjects & Total No. \\
1 & No of children referred to DEIC & 8911 \\
2 & No of children with speech difficulty & 380 \\
3 & No of children with speech difficulty diagnosed with & $304(80 \%)$ \\
\hline \multicolumn{3}{|c|}{ ankyloglossia } \\
\hline
\end{tabular}

\begin{tabular}{|cc|}
\hline Sex & Speech Difficulty with Ankyloglossia \\
Male & $193(63.5 \%)$ \\
Female & $111(36.5 \%)$ \\
\hline & Table 2. Sex Distribution of Ankyloglossia \\
\hline
\end{tabular}

\begin{tabular}{|ccc|}
\hline Sl. No. & Types of Lingual Frenulum & Percentage \\
1 & Type 1 & $5(1.6 \%)$ \\
2 & Type 2 & $220(72 \%)$ \\
3 & Type 3 & $70(23 \%)$ \\
4 & Type 4 & $9(3 \%)$ \\
\hline \multicolumn{2}{|c|}{ Table 3. Distribution of Types of Ankyloglossia } \\
\hline
\end{tabular}

\section{DISCUSSION}

The prevalence of ankyloglossia is less investigated in the available scientific database. In our study the overall prevalence of ankyloglossia was 3.4 percent. In the literature the estimates range from 0.02 to 10.7 percent. ${ }^{4}$ However the wide range of distribution was attributed to variations in definition, diagnostic criteria and also different groups of study population. Our department being a tertiary care referral centre the prevalence recorded was towards the lower range which could be because of referral factors including lack of awareness, non-identification of the condition and lack of referral due to minimal symptoms, target population including only government and aided schools. Also, the visual inspection method to diagnose ankyloglossia in the school referral centers can contribute to under diagnosis, as type 3 and 4 require palpation for diagnosis.

There is still a void in the knowledge on association between speech and ankyloglossia. In our study the prevalence of ankyloglossia in children with speech difficulty was 80 percent. This higher prevalence indicates the importance of oral examination for ankyloglossia in all children with speech difficulty. Though the onset of speech is not affected by ankyloglossia, it does affect the articulation. However, definitive evidence is lacking to address the relationship between speech and ankyloglossia. Few studies support that speech outcomes had improved following surgical correction of ankyloglossia. On the contrary Dollberg et $\mathrm{al}^{5}$ and Webb $\mathrm{A}$ et $\mathrm{al}^{6}$ reported that there is no 
improvement in speech outcome following ankyloglossia correction. The study by Daggumati et $\mathrm{al}^{7}$ demonstrated that there was satisfactory improvement in speech following frenectomy by comparing with minimal improvement in those who did not undergo surgical correction. Also, many children with ankyloglossia are often found to have no speech problem or they gradually overcome the problem. ${ }^{8}$ In our study higher proportion of ankyloglossia was observed in male children with 63.5 percent and in females it was only 36.5 percent. Jonathan Walsh et $\mathrm{al}^{9}$ reported a similar greater male incidence of 63.5 percent. Ballard et al ${ }^{10}$ also reported a higher incidence in males with a ratio of 1.5-2.6:1. The male predominance suggests the possibility of X linked inheritance.

Among the different types of ankyloglossia, type 2 was highly prevalent (72 percent) and type 1 was the least prevalent (1.6 percent) than the other types. Careful digital palpation enabled identification of type 4 frenulum with prevalence of 9 percent as they go under diagnosed with only visual inspection. The study by Ferres Amat et al reported the type 3 frenulum as the most frequent type (59.6 percent) followed by type 2 frenulum ( 26.9 percent). ${ }^{11}$ Gonzalez JD et al reported type 2 as the most prevalent frenulum type (54 percent). ${ }^{12}$ However study by $0^{\prime}$ Callahan ${ }^{13}$ reported a higher frequency of type 4 frenulum, thus insisting significance on the factor of relative subjective bias in diagnosis and referral.

\section{CONCLUSIONS}

To conclude, a substantial proportion of children with speech problem had ankyloglossia (80 percent) insisting that all children with speech difficulty should be screened for ankyloglossia and correction undertaken. This study thus signified the impact of ankyloglossia on speech. Hence awareness should be created among the common people about ankyloglossia and the treatment options available, so that they can be treated at the earliest.

\section{REFERENCES}

[1] Kotlow L. Diagnosis and treatment of ankyloglossia and tied maxillary fraenum in infants using Er: YAG and 1064 diode lasers. Eur Arch Paediatr Dent 2011;12(2):106-12.
[2] Suter VGA, Bornstein MM. Ankyloglossia: facts and myths in diagnosis and treatment. J Periodontol 2009;80(8):1204-19.

[3] Messner AH, Lalakea ML. The effect of ankyloglossia on speech in children. Otolaryngol Head Neck Surg 2002;127(6):539-45.

[4] Chaubal TV, Dixit MB. Ankyloglossia and its management. J Indian Soc Periodontol 2011;15(3):2702.

[5] Dollberg S, Manor Y, Makai E, et al. Evaluation of speech intelligibility in children with tongue-tie. Acta Paediatr 2011;100(9):e125-7.

[6] Webb AN, Hao W, Hong P. The effect of tongue-tie division on breastfeeding and speech articulation: a systematic review. Int $\mathrm{J}$ Pediatr Otorhinolaryngol 2013;77(5):635-46.

[7] Daggumati S, Cohn JE, Brennan MJ, et al. Speech and language outcomes in patients with ankyloglossia undergoing frenulectomy: a retrospective pilot study. OTO Open 2019;3(1):2473974X19826943.

[8] Lalakea ML, Messner AH. Ankyloglossia: Does it matter? Pediatr Clin North Am 2003;50(2):381-97.

[9] Walsh J, Links A, Boss E, et al. Ankyloglossia and lingual frenotomy: National Trends in Diagnosis and Management in The United States, 1997-2012. Otolaryngol Head Neck Surg 2017;156(4):735-40.

[10] Ballard JL, Auer CE, Khoury JC. Ankyloglossia: assessment, incidence and effect of frenuloplasty on the breastfeeding dyad. Pediatrics 2002;110(5):e63.

[11] Ferres-Amat E, Pastor-Vera T, Rodriguez-Alessi P, et al. The prevalence of ankyloglossia in 302 newborns with breastfeeding problems and sucking difficulties in Barcelona: a descriptive study. Eur J Peadiatr Dent 2017;18(4):319-25.

[12] Jimenez GD, Romero CM, Galan RL, et al. Prevalence of ankyloglossia in newborns in Austrias (Spain). An Pediatr (Barc) 2014;81(2):115-9.

[13] O'Callahan C, Macary S, Clemente S. The effects of officebased frenotomy for anterior and posterior ankyloglossia on breast-feeding. Int J Pediatr Otorhinolaryngol 2013;77(5):827-32. 